\title{
EFFECT OF ORIENTATIONAL STRENGTHENING OF POLYMERIC MATERIAL ON MECHANICAL PROPERTIES OF PRODUCTS
}

The research deals with the problem of mathematical modeling of bending of polymeric beams. Polymeric materials today play a leading role in the manufacture of various parts in all industries. In this connection it is important to determine the characteristics of such products and predict their behavior in various conditions. Mechanical properties of the strengthened polymeric parts do not meet Hooke's law; therefore, the problem of the determination of their stress and strain state cannot be solved by classical methods of strength of materials and theory of elasticity. It is difficult to predict behavior of strengthened polymeric parts under loading, so it is important to evolve the method for calculation stress and deformation in most frequently occurring situation such as bending. Aim: The purpose of the research is to obtain a mathematical model that describes stress and strain in bending doubly-supported beams made of polymeric materials. Materials and Methods: Experimental research of bending doubly-supported beams was performed using samples of hardened high-density polyethylene according to the standard method of static bending test for plastics. Originality: The mathematical model of bending of polymeric beam under load force applied to its middle section is evolved. The mathematical model describes the dependence of stress and strain on the loading force at bending of solid and hollow polymeric beams. The expressions for calculating stress occurring in the material of the beam and its deformation are obtained. Results: Experimental studies have confirmed the correctness of the developed mathematical model which allows offering the obtained analytical expressions for calculation plastic parts for strength and rigidity. The results can be used in the design of structural elements of machines and appliances, products of light industry.

Keywords: strength; deformation; bending; polymeric beam.

Problem statement. Various parts manufactured from polymeric materials are being wieldy used in contemporary science and engineering. One of the most effective methods of increasing the strength of polymeric parts is to provide orientation of their structure in the direction of loading. In the process of injection molding a high degree of orientation of polymer structure can be provided by solidification of the melt during its flow.

Analysis of recent research and publications. Mechanical properties of the strengthened polymeric parts do not meet Hooke's law; therefore, the problem of the determination of their stress and strain state cannot be solved by classical methods of strength of materials and theory of elasticity [1-7]. Thus, to predict behavior of strengthened polymeric parts under loading it is important to evolve the method for calculation stress and deformation in most frequently occurring situation such as bending.

Aim of the research. The purpose of the research is to obtain a mathematical model that describes stress and strain in bending doubly-supported beams made of polymeric materials. Experimental research of bending doubly-supported beams was performed using samples of hardened high-density polyethylene according to the standard method of static bending test for plastics.

Statement of the material. Let us make use of the known connection function between deformation and stress in polymeric materials [8]:

$$
\sigma^{m}=E \varepsilon,
$$

where $\sigma$ - normal tension in cross-section;

$m$ - exponent which varies from 0.6 to 1 (when $m=1$ the body has the elastic properties);

$E$ - modulus of elasticity of the material sample;

$\varepsilon$ - relative elongation of a sample.

Consider pure bending of a beam for which the bending moment is [9]:

$$
\int_{A} \sigma z d A=M
$$

where $M$ - the bending moment;

$z$ - the distance from the neutral axis;

$d A$ - an element of cross-sectional area.

Relative elongation of a beam's fiber is [9]:

(C) T.I. Kulik, 2017 


$$
\varepsilon=\frac{z}{r},
$$

where $r$ - the radius of the bend.

From (1) follows:

$$
\sigma=(E \varepsilon)^{\frac{1}{m}} \text {. }
$$

Substituting (3) into (4) we obtain:

$$
\sigma=\left(E \frac{z}{r}\right)^{\frac{1}{m}} \text {. }
$$

Substituting (5) into (2) we get:

$$
\int_{A}\left(E \frac{z}{r}\right)^{\frac{1}{m}} z d A=M .
$$

Let us rewrite (6) as:

$$
\left(\frac{E}{r}\right)^{\frac{1}{m}} \int_{A} z^{\frac{1}{m}+1} d A=M .
$$

Let us denote the integral in (7) as:

$$
I_{m}=\int_{A} z^{\frac{1}{m}+1} d A .
$$

In view of (7) and (8), we have:

$$
\left(\frac{E}{r}\right)^{\frac{1}{m}}=\frac{M}{I_{m}} \text {. }
$$

To determine the stress transform (5) to the form:

$$
\left(\frac{E}{r}\right)^{\frac{1}{m}}=\frac{\sigma}{z^{\frac{1}{m}}} .
$$

Substituting (10) into (9) we get:

$$
\sigma=\frac{M z^{\frac{1}{m}}}{I_{m}} .
$$

or

$$
I_{m}=\frac{M z^{\frac{1}{m}}}{\sigma} .
$$

Integral (8) for beams of rectangular cross-section can be represented as:

$$
I_{m}=\int_{A} z^{\frac{1}{m}+1} d A=\int_{-h / 2}^{h / 2} z^{\frac{1}{m}+1} b d z=b \int_{-h / 2}^{h / 2} z^{\frac{1}{m}+1} d z=\frac{b}{\frac{1}{m}+2}\left[z^{\frac{1}{m}+2}\right]_{-h / 2}^{h / 2}=\frac{2 b}{\frac{1}{m}+2}\left(\frac{h}{2}\right)^{\frac{1}{m}+2}
$$

To determine the deformation transform (9) to the form:

$$
\frac{1}{r}=\frac{M^{m}}{E I_{m}^{m}}
$$

For small deformations of the beam it can be considered that [6]:

$$
\frac{1}{r}=\frac{d^{2} y}{d x^{2}}
$$

Substituting (15) into (14) we get:

$$
E I_{m} \frac{d^{2} y}{d x^{2}}=M^{m}
$$

Consider deformation of a beam which is loaded according to the scheme discussed in [10] (Fig. 1). 


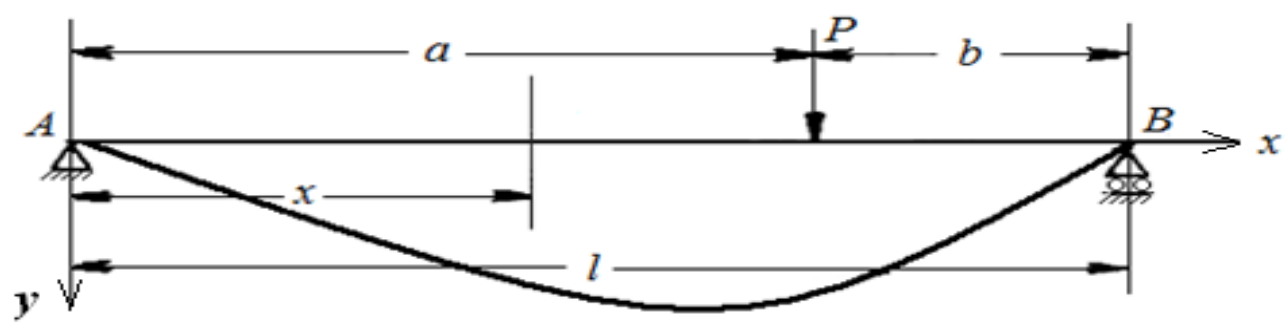

Fig. 1. Scheme of the beam's deformation

In this case, we can write two equations for the bending moment [10]:

$$
\begin{aligned}
& E I_{m} \frac{d^{2} y}{d x^{2}}=\left(-\frac{P}{2} x\right)^{m} \text { for } x \leq a \\
& E I_{m} \frac{d^{2} y}{d x^{2}}=\left[-\frac{P}{2} x+P\left(x-\frac{l}{2}\right)\right]^{m} \text { for } x \geq a .
\end{aligned}
$$

Integrating equation (17), we get:

$$
E I_{m} \frac{d y}{d x}=\left(-\frac{P}{2}\right)^{m} \frac{1}{m+1} x^{m+1}+C .
$$

If the force is applied in the middle of the beam at $x=\frac{l}{2}$ the angle of rotation beam's axis will be $\frac{d y}{d x}=0$.

From this condition, according to (19) we define the constant of integration C :

$$
C=\left(\frac{P}{2}\right)^{m} \frac{1}{m+1}\left(\frac{l}{2}\right)^{m+1} \text {. }
$$

Substituting (20) into (19), we get:

$$
E I_{m} \frac{d y}{d x}=\left(-\frac{P}{2}\right)^{m} \frac{1}{m+1} x^{m+1}+\left(\frac{P}{2}\right)^{m} \frac{1}{m+1}\left(\frac{l}{2}\right)^{m+1} .
$$

From (21) the angle of rotation of beam's axis is determined as:

$$
\theta=\frac{d y}{d x}=\frac{1}{E I_{m}}\left[\left(-\frac{P}{2}\right)^{m} \frac{1}{m+1} x^{m+1}+\left(\frac{P}{2}\right)^{m} \frac{1}{m+1}\left(\frac{l}{2}\right)^{m+1}\right] .
$$

Integrating (21), we get:

$$
E I_{m} y=\left(-\frac{P}{2}\right)^{m} \frac{1}{m+1} \frac{1}{m+2} x^{m+2}+\left(\frac{P}{2}\right)^{m} \frac{1}{m+1}\left(\frac{l}{2}\right)^{m+1} x+C_{1} .
$$

Deflection of the beam at $x=0$ will be $y=0$. From this condition, according to (23) we find the value of the constant $C_{1}$ :

$$
C_{1}=0 .
$$

After substituting (24) into (23), we get:

$$
E I_{m} y=\left(-\frac{P}{2}\right)^{m} \frac{1}{(m+1)(m+2)} x^{m+2}+\left(\frac{P}{2}\right)^{m} \frac{1}{m+1}\left(\frac{l}{2}\right)^{m+1} x .
$$

From (25) we define the beam's deflection:

$$
y=\frac{1}{E I_{m}}\left[\left(-\frac{P}{2}\right)^{m} \frac{1}{(m+1)(m+2)} x^{m+2}+\left(\frac{P}{2}\right)^{m} \frac{1}{m+1}\left(\frac{l}{2}\right)^{m+1} x\right] .
$$

If the force is applied in the middle of the beam, at $x=a=b=l / 2$ the maximum deflection will also be in this place and can be determined from (26):

$$
y_{\max }=\frac{1}{E I_{m}}\left[\left(-\frac{P}{2}\right)^{m} \frac{1}{(m+1)(m+2)}\left(\frac{l}{2}\right)^{m+2}+\left(\frac{P}{2}\right)^{m} \frac{1}{m+1}\left(\frac{l}{2}\right)^{m+1} \frac{l}{2}\right] .
$$

The maximum angle of rotation of beam's axis will be at $x=0$ and can be determined from (22): 


$$
\theta_{\max }=\frac{d y}{d x}=\frac{1}{E I_{m}}\left[\left(\frac{P}{2}\right)^{m} \frac{1}{m+1}\left(\frac{l}{2}\right)^{m+1}\right] .
$$

To verify the analytical dependences the experiments on stretching and bending of beams from strengthened polyethylene of low density were performed.

To determine the parameters of equation (1), let us logarithm its left and right parts:

$$
\lg \left(\sigma^{m}\right)=\lg (E \varepsilon) \text {. }
$$

Let us transform (29) to the form:

$$
\lg (\varepsilon)=-\log (E)+m \lg (\sigma) .
$$

The values of parameters $E$ and $m$ can be determined from the dependence (30).

As a result of the conducted experiments on stretching the regression equation was obtained in the form:

$$
\lg (\varepsilon)=1,0768 \lg (\sigma)-9,7679 .
$$

From the equation (31) the values of the parameters $E$ and $m$ were determined: $E=10^{8,4} \mathrm{~N} / \mathrm{m}^{2} ; m \approx 1,1$.

Based on experimental data registered at bending samples with a length of $70 \mathrm{~mm}$ and a square crosssection 6 by $6 \mathrm{~mm}$ the regression equation was obtained:

$$
y_{\max }=1,329 \cdot 10^{-4} \cdot P+7.099 \cdot 10^{8} \cdot P^{2} .
$$

Figure 2 shows graphs calculated by analytical formula (27) and the experimental regression equation (32).

The discrepancy between analytical (27) and experimental (32) dependencies does not exceed $10 \%$.

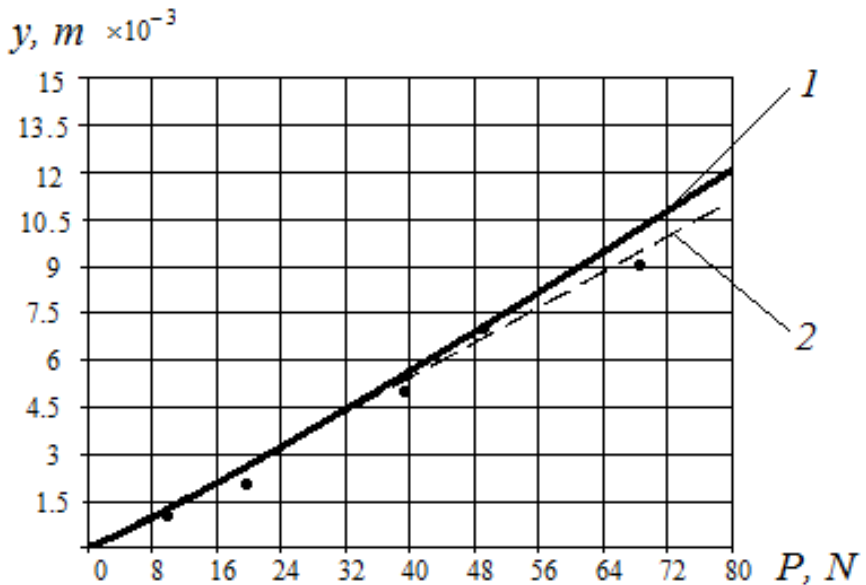

Fig. 2. Dependence of beam's maximum deflection on load: 1 - analytical; 2 - experimental

Results and recommendations for further research. The mathematical model of bending of polymeric beam under load force applied to its middle section is evolved. The expressions for calculating stress occurring in the material of the beam and its deformation are obtained. Experimental studies have confirmed the correctness of the developed mathematical model which allows offering the obtained analytical expressions for calculation plastic parts for strength and rigidity.

\section{References:}

1. Biani, A. Mechanical behaviour of cyclic olefin copolymer/exfoliated graphite nanoplatelets nanocomposites foamed through supercritical carbon dioxide / A.Biani, A.Dorigato, M.Slouf, A.Pegoretti // Express Polymer Letters. - 2016. - Vol. 10 (12). - Pp. 977-989.

2. Agarwal, S. Functional materials by electrospinning of polymers / S.Agarwal, A.Greiner, J.H. Wendorff // Progress in Polymer Science. - 2003. - Vol. 38, no 6. - Pp. 963-991.

3. Aly, A.A. Enhancement in mechanical properties of polystyrene filled with carbon nano particulates (CNPS) / A.A. Ayman, M.M. Mahmoud, A.A. Omer // World Journal of Nano Science and Engineering (WJNSE). - 2012. Vol. 2, no. 2. - Pp. $103-109$.

4. Samuel, O.D. Assessing mechanical properties of natural fibre reinforced composites for engineering applications / O.D. Samuel, S.Agbo, T.A. Adekanye // Journal of Minerals and Materials Characterization and Engineering. 2012. - Vol. 11. - Pp. 780-784.

5. Arao, Y. Strength improvement in injection-molded jute-fiber-reinforced polylactide green-composites / Y.Arao, T.Fujiura, S.Itani, T.Tanaka // Composites. Part B : Engineering. - 2015. - Vol. 68. - Pp. 200-206. 
6. Ahmed, M.S. Theoretical modal analysis of freely and simply supported RC slabs / M.S. Ahmed, F.A. Mohammad // International Journal of Mechanical, Aerospace, Industrial and Mechatronics Engineering. - 2014. - Vol. 8. - Pp. 2026-2030.

7. Alavudeen, A. Mechanical properties of banana/kenaf fiber-reinforced hybrid polyester composites : effect of woven fabric and random orientation / A.Alavudeen, N.Rajini, K.Subramanian, M.Thiruchitrambalam, N.Venkateshwaren // Materials and Design. - 2015. - Vol. 66. - Pp. 24-257.

8. Kulik, T.I. Strength and deformation of polymer pieces at the light industry / T.I. Kulik, O.P. Burmistenkov, B.M. Zlotenko // Odes'kyi Politechnichnyi Universytet. Pratsi. - 2015. - Vol. 2 (46). - Pp. 62-68.

9. Belyaev, N.M. Strength of materials / N.M. Belyaev. - M. : Mir, 1979. - 648 p.

10. Timoshenko, S.P. Strength of Materials / S.P. Timoshenko. - New York : Van Nostad Reinhold, 1948. - 510 p.

\section{References:}

1. Biani, A., Dorigato, A., Bonani, W., Slouf, M. and Pegoretti, A. (2016), «Mechanical behaviour of cyclic olefin copolymer/exfoliated graphite nanoplatelets nanocomposites foamed through supercritical carbon dioxide», Express Polymer Letters, Vol. 10 (12), pp. 977-989.

2. Agarwal, S., Greiner, A. and Wendorff, J. (2013), «Functional materials by electrospinning of polymers», Progress In Polymer Science, Vol. 38 (6), pp. 963-991.

3. Aly, A., Mahmoud, M. and Omar, A. (2012), «Enhancement in Mechanical Properties of Polystyrene Filled with Carbon Nano-Particulates (CNPS)», World Journal Of Nano Science And Engineering, Vol. 2, no. 2, pp. 103-109.

4. Samuel, O., Agbo, S., and Adekanye, T. (2012), «Assessing Mechanical Properties of Natural Fibre Reinforced Composites for Engineering Applications», Journal Of Minerals And Materials Characterization And Engineering, Vol. 11 (08), pp. 780-784.

5. Arao, Y., Fujiura, T., Itani, S., and Tanaka, T. (2015), «Strength improvement in injection-molded jute-fiberreinforced polylactide green-composites», Composites, Part B: Engineering, Vol. 68, pp. 200-206.

6. Ahmed, M.S. and Mohammad, F.A. (2014), «Theoretical modal analysis of freely and simply supported RC slabs», International Journal of Mechanical, Aerospace, Industrial, Mechatronic and Manufacturing Engineering, Vol. 8 (12), pp. 2026-2030.

7. Alavudeen, A., Rajini, N., Karthikeyan, S., Thiruchitrambalam, M. and Venkateshwaren, N. (2015), «Mechanical properties of banana/kenaf fiber-reinforced hybrid polyester composites: Effect of woven fabric and random orientation», Materials \& Design, Vol. 66, pp. 246-257.

8. Kulik, T., Burmistenkov, O. and Zlotenko, B. (2015), «Strength and deformation of polymer pieces at the light industry», Odes 'Kyi Politechnichnyi Universytet, Pratsi, Vol. 2 (46), pp. 62-68.

9. Belyaev, N.M. (1979), Strength of materials, 1st ed., Mir Publishers, Moscow, 648 p.

10. Timoshenko, S.P. (1948), Strength of materials, 1st ed., Van Nostrand Reinhold, New York, 510 p.

KULIK Tetiana - PhD, Assoc. Prof., Department of Electromechanical Systems, Kyiv National University of Technologies and Design.

Scientific interests:

- injection molding;

- footwear technology.

Tel.: (097)-30-90-470.

E-mail: t-81@ukr.net. 